From the American Academy of Family Physicians

Ann Fam Med 2004;2:377-378. DOI: 10.1370/afm.209.

\section{PILOT PROJECT STUDIES EHR IMPLEMENTATION ISSUES}

President Bush has made implementation of electronic health records (EHRs) a priority and wants EHRs used nationwide by 2010 .

The American Academy of Family Physicians (AAFP) has a more ambitious goal: to have $50 \%$ of active members using EHRs by the end of 2005.

To help make that goal a reality, the Academy is conducting a pilot project that should find out exactly what it will take to implement an EHR system in a family medicine setting.

"I think of this pilot project as a 'real world laboratory' in which our family physicians are working together with some of the very best and innovative IT companies to help design a low-cost, standards-based EHR option that could eventually be used by many thousands of practices," said David C. Kibbe, MD, director of AAFP's Center for Health Information Technology. "The family physicians are also learning how to overcome problems encountered with implementation, connectivity, and training."

How did the Academy find members willing to participate? Simple. It asked for volunteers. Six FPs, from practices scattered across the country, were chosen from 21 applicants. The physicians-along with technical support teams from MedPlexus, Inc, Hewlett-Packard, and Siemens Medical Solutions Health Services Corp-have been immersed in the pilot since January. The companies are partners in AAFP's EHR initiative, Partners for Patients.

The FPs in the pilot are John Sattenspiel, MD, of Salem, Ore, a member of the AAFP Board of Directors; John Wilson, MD, of Daly City, Calif, Kenneth Bertka, MD, of Holland, Ohio; Michael Peterson, MD, of Herriman, Utah, Desiree Butter, MD, of Pittsburgh, $\mathrm{Pa}_{\text {; }}$ and Ronald Hughes, MD, of Whitakers, NC.

\section{Tracking Work Flow}

One of the first steps in the pilot project was to track each physician's office work flow before implementing an EHR system. That task fell to Edmund Billings, MD, president of Phyxe, a consulting company that helps physicians define, validate, and adopt new products.

Five of the practices gave self-reports on a set of detailed criteria Billings provided. Questions included: How many people are on your staff? How are tasks assigned? How many patient visits do you log each day? How many prescriptions do you write and how many charts are pulled?

Wilson's solo practice received an onsite visit from Billings. "We videotaped Dr. Wilson and his medical assistant and logged everything they did for a full day. We captured each task and measured the time spent on each," said Billings. Every time Wilson took a call for a referral or a prescription refill, Billings logged the time of the call and the actions it initiated, such as pulling a chart. "There was a detailed analysis of the work flow," he said.

At the pilot's conclusion, Billings will revisit Wilson's practice and measure the impact of the EHR product on work flow. "I'll be interested in seeing how my day has changed," said Wilson. "Did it (the EHR system) change how I interact with my patients?"

\section{Equipment Bells and Whistles}

The pilot participants were set up with an EHR system featuring an extensive internal messaging system; an HP Tablet PC TC1100, a pen-based tablet computer system that also allows for free-text entry into a note; and a powerful voice recognition engine. There's also a prescription-writing module. "I can generate a refill prescription with a couple of pen taps on my tablet," said Sattenspiel. The prescription is automatically faxed to the local pharmacy.

Hewlett-Packard provided nearly 30 computers-Tablet PCs and D530 Business Desktops-for the project. At the of the project, the physicians will have the option to buy their computers at a discounted rate.

\section{Getting Started}

The physicians realized early on in the pilot project that built-in templates would save them time. "We came up with our most common diagnoses and created templates, and now we've got a small library to get started with," said Wilson.

He and the other physicians are still getting used to the equipment. In IT terms, they're all in "sandbox mode."

"This is a place where we can play with the software," said Sattenspiel. "I can generate notes, enter patient information, and basically play around with it to my heart's content."

The sandbox period gives physicians a chance to learn the system, practice the flow, and make mistakes before going into a live production mode, said Denny Koch, MedPlexus, vice president of operations.

The physicians and support teams have regular telephone conferences and access to a private online site where they address problems and discuss solutions. 
When a physician encounters a software glitch, the MedPlexus support team quickly finds a fix and then supplies an upgrade via the Internet. "People are really responding to our needs. Every significant upgrade that MedPlexus has provided has been a dramatic step forward," said Wilson.

Sometime this summer, all 6 practices will leave the sandbox and go into production mode. When they do, they'll be operating in real time, "seeing real patients and using the system," said Koch.

Wilson can't wait. "My only frustration is I want the project to move even faster," he said. Wilson will phase in the system by entering every new patient into an electronic chart. Next he'll add complicated patients that have long medical problem sheets and medication lists. The final tier will be other established patients.

\section{Dealing With the Learning Curve}

Sattenspiel said he wants to find out how disruptive EHR implementation will be to his practice. "Everyone in the office has to be on board" because the EHR system will change how the practice does everything, he said.

"How much is it going to slow us down?" asked Sattenspiel. "If we go to a system like this and begin to implement it, we may not be drowning in paper every day, but if we can't get enough work done-if we can't see enough patients in a reasonable amount of time to be able to generate the revenues that will support our office-then that could be a disaster."
The absolute expectation is than an EHR will speed things up, but the pilot project needs to define the steepness of the learning curve and get a handle on how much implementation will cost, said Sattenspiel. "If we lost $25 \%$ of our production for 3 months because we're learning how to use this system-that puts us at financial risk."

\section{Future Steps}

The pilot project will conclude by the end of 2004. The information generated will be compiled into a final report so the information gathered-and questions answeredcan be put to use. A second phase may follow.

"We think physicians will adopt new technologies if we engage them in a conversation about improving their practices," said Billings. At the end of the day, physicians will discover what best works for them and share what they've learned with other physicians. "Physicians really trust each other," said Billings.

And what of those pioneering FPs who volunteered for this mission? They will know they mapped the glitches and successes of EHR implementation for their colleagues who inevitably will follow in their footsteps.

EHR implementation "is the direction in which we all need to go if we're going to provide the best-quality patient care," said Sattenspiel.

Sheri Porter AAFP News Department 